\title{
The Trem2 R47H Alzheimer's risk variant impairs splicing and reduces Trem2 mRNA and protein in mice but not in humans
}

\author{
Xianyuan Xiang ${ }^{1,2}$, Thomas M. Piers ${ }^{3}$, Benedikt Wefers ${ }^{4,6}$, Kaichuan Zhu ${ }^{4,5}$, Anna Mallach ${ }^{3}$, Bettina Brunner ${ }^{4}$, \\ Gernot Kleinberger ${ }^{1,5}$, Wilbur Song ${ }^{7}$, Marco Colonna ${ }^{7}$, Jochen Herms ${ }^{4,5,8}$, Wolfgang Wurst ${ }^{4,5,6,9}$, \\ Jennifer M. Pocock ${ }^{3}$ and Christian Haass ${ }^{1,4,5^{*}}$
}

\begin{abstract}
Background: The R47H variant of the Triggering Receptor Expressed on Myeloid cells 2 (TREM2) significantly increases the risk for late onset Alzheimer's disease. Mouse models accurately reproducing phenotypes observed in Alzheimer' disease patients carrying the R47H coding variant are required to understand the TREM2 related dysfunctions responsible for the enhanced risk for late onset Alzheimer's disease.

Methods: A CRISPR/Cas9-assisted gene targeting strategy was used to generate Trem2 R47H knock-in mice. Trem2 mRNA and protein levels as well as Trem2 splicing patterns were assessed in these mice, in iPSC-derived human microglia-like cells, and in human brains from Alzheimer's patients carrying the TREM2 R47H risk factor.

Results: Two independent Trem2 R47H knock-in mouse models show reduced Trem2 mRNA and protein production. In both mouse models Trem2 haploinsufficiency was due to atypical splicing of mouse Trem2 R47H, which introduced a premature stop codon. Cellular splicing assays using minigene constructs demonstrate that the R47H variant induced abnormal splicing only occurs in mice but not in humans. TREM2 mRNA levels and splicing patterns were both normal in iPSC-derived human microglia-like cells and patient brains with the TREM2 R47H variant.
\end{abstract}

Conclusions: The Trem2 R47H variant activates a cryptic splice site that generates miss-spliced transcripts leading to Trem2 haploinsufficiency only in mice but not in humans. Since Trem2 R47H related phenotypes are mouse specific and do not occur in humans, humanized TREM2 R47H knock-in mice should be generated to study the cellular consequences caused by the human TREM2 R47H coding variant. Currently described phenotypes of Trem2 $\mathrm{R} 47 \mathrm{H}$ knock-in mice can therefore not be translated to humans.

Keywords: Alzheimer's disease, Microglia, Neurodegeneration, TREM2, Pre-mRNA splicing, Human microglia

\section{Background}

Microgliosis has long been thought to play a central role in the initiation and progression of Alzheimer's disease (AD) pathology. Indeed, genetic analyses recently revealed risk variants in a number of genes exclusively or at least preferentially expressed in microglia [1-5]. Among these, the gene encoding the triggering receptor

\footnotetext{
*Correspondence: christian.haass@mail03.med.uni-muenchen.de

${ }^{1}$ Metabolic Biochemistry, Biomedical Center (BMC), Faculty of Medicine,

Ludwig-Maximilians-Universität München, Munich, Germany

${ }^{4}$ German Center for Neurodegenerative Diseases (DZNE) Munich, Munich,

Germany

Full list of author information is available at the end of the article
}

expressed on myeloid cells 2 (TREM2) plays a pivotal role in regulating microglial activity [6-9]. As part of the disease associated signature of microglia (DAM; also called MGnD (microglia neurodegenerative disease)), TREM2 is one of the most upregulated genes when microglia encounter acute injuries within the brain or respond to neurodegenerative disorders such as $\mathrm{AD}$ and amyotrophic lateral sclerosis $[6,10]$. Moreover, absence of functional TREM2 caused by a gene knockout or certain disease-associated sequence variants, which misfold TREM2 and retain the protein within the endoplasmic reticulum, lock microglia in a homeostatic state and

(C) The Author(s). 2018 Open Access This article is distributed under the terms of the Creative Commons Attribution 4.0 International License (http://creativecommons.org/licenses/by/4.0/), which permits unrestricted use, distribution, and 
prevent their activation in vivo $[7,11]$. As a consequence cellular defense mechanisms such as chemotaxis, prominently visible by the lack of clustering around amyloid plaques, proliferation, phagocytosis of dead cells and amyloid fibrils are all reduced [8, 12, 13]. Furthermore, overexpression of human wild-type (wt) TREM2 in a Trem2 knockout mouse corrects loss-of-function phenotypes [14]. Thus TREM2 is believed to have protective functions. In line with that, TREM2 is upregulated early during disease development. In a study on patients with dominantly inherited AD (DIAN), soluble TREM2 was found to be increased 5 years before onset of clinical symptoms, which may also be interpreted as a protective response [15]. Consistent with this conclusion, lack of functional TREM2 affects amyloid plaque morphology and increases plaque associated neuritic dystrophies $[13,16]$. Furthermore, in models of acute neuronal injury such as the cuprizone model, Trem2 activity facilitates clearance of cellular debris and recovery [11, 17, 18]. For tauopathies there are, however, opposing results indicating either protective or detrimental functions $[19,20]$. In line with findings in mouse models for amyloid plaque pathology, this may be due to stage specific functions of Trem2.

Mouse models and cellular systems greatly helped to understand the consequences of loss-of-function mutations / haploinsufficiency of TREM2. However, the most important disease variant, namely $\mathrm{R} 47 \mathrm{H}$, which has been shown to increase the risk for late onset AD to a similar extent as the Apo lipoprotein E (ApoE) \&4 allele [3, 4], has been much less investigated. In cultured cells TREM2 R47H reduces ligand binding [8, 21-23]. Consistent with a pivotal role in ligand binding, structural analyses revealed that arginine 47 is required to stabilize a conformation, which is capable to interact with ligands such as ApoE and phosphatidylserine [24]. Furthermore maturation of the $\mathrm{R} 47 \mathrm{H}$ variant within the secretory pathway may also be delayed [25]. In line with these findings, expression of human TREM2 $\mathrm{R} 47 \mathrm{H}$ in Trem2 knockout mice failed to rescue their phenotypes [14]. These findings may therefore be indicative of a loss-of-function. In fact, very recently CRISPR/Cas9 generated mouse models expressing the $\mathrm{R} 47 \mathrm{H}$ variant within the endogenous Trem 2 mouse locus revealed a significant loss-of function $[26,27]$. Trem2 $\mathrm{R} 47 \mathrm{H}$ mice exhibited reduced Trem2 upregulation in microglia, reduced microgliosis, reduced clustering around amyloid plaques and an overall reduction of Trem2 protein [26]. Haploinsufficiency of Trem 2 was confirmed by a significant reduction of Trem 2 mRNA derived from the mutant allele [26]. Thus heterozygous Trem2 R47H mice appear to phenocopy a heterozygous knockout of Trem2.

We also independently generated Trem2 R47H knock-in mice using the CRISPR/Cas9 technology and reproduced haploinsufficiency of Trem 2 in this model.
Moreover, we could demonstrate that reduced mRNA stability due to a splicing error leads to a severe reduction of Trem 2 mRNA. However, aberrant splicing was mouse specific and could not be observed in humans. Thus phenotypes associated with the $\mathrm{R} 47 \mathrm{H}$ variant inserted into the endogenous mouse locus may not allow conclusions on the cellular mechanisms affected in humans.

\section{Methods \\ Mice}

Animal handling and animal experiments were performed in accordance to local animal laws and housed in standard cages in a specific pathogen-free facility on a 12-h light/dark cycle with ad libitum access to food and water.

Jax Trem2 R47H knock-in mice were purchased from Jackson laboratory. In-house Trem $2 \mathrm{R} 47 \mathrm{H}$ knock-in mice were generated using CRISPR/Cas9 technology in C57BL/6 N background. Both strains were housed and bred in the same animal facility. To extract bone marrow, mice were first euthanized by $\mathrm{CO}_{2}$ followed by cervical dislocation.

\section{Generation of Trem2 R47H knock-in mice}

Trem2 R47H knock-in mice (R47H ki mice) were generated by CRISPR/Cas9-assisted gene targeting in zygotes as described previously $[28,29]$. Briefly, pronuclear stage zygotes were obtained by mating $\mathrm{C} 57 \mathrm{BL} / 6 \mathrm{~N}$ males with superovulated C57BL/6 N females (Charles River). Embryos were then microinjected into the male pronucleus with an injection mix containing $25 \mathrm{ng} / \mu \mathrm{l}$ Cas 9 mRNA, $12.5 \mathrm{ng} / \mu \mathrm{l}$ Trem2-specific sgRNA, and $25 \mathrm{ng} / \mu \mathrm{l}$ singlestranded oligodeoxynucleotide (ssODN). Cas9 mRNA was prepared from XbaI-linerized pCAG-Cas9v2-162A by in vitro transcription using the mMESSAGE mMACHINE ${ }^{\mathrm{mu}}$ T7 ULTRA Transcription Kit (Thermo Fisher Scientific, \#AM1345) and purified using the MEGAclear ${ }^{\text {ra }}$ Transcription Clean-Up Kit (Thermo Fisher Scientific, \#AM1908). Trem2-specific sgRNA (protospacer: GAAGCACTG GGGGAGACGCA) was prepared by IVT from pBS-T7sgTrem2 using the MEGAshortscript ${ }^{\text {ti }}$ T7 Transcription Kit (Thermo Fisher Scientific, \#AM1354) and purified with

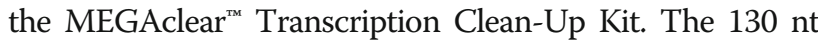
ssODN targeting molecule ssTrem2 R47H (5'- GGGC ATGGCCGGCCAGTCCTTGAGGGTGTCATGTACTTA TGACGCCTTGAAGCACTGGGGTCGACACAAAGCC TGGTGTCGGCAGCTGGGTGAGGAGGGCCCATGCC AGCGTGTGGTGAGCACACACGGT -3'), comprising the $\mathrm{G}>\mathrm{A}$ substitution (underlined) and three additional silent mutations (bold), was synthetized by Metabion. After microinjection, zygotes were cultured in KSOM medium until they were transferred into pseudopregnant CD-1 foster animals. 


\section{Off-target analysis of Trem2 R47H mice}

To identify putative off-target sites of the Trem2-specific sgRNA, the online tool CRISPOR (http://crispor.tefor.n et/) [30] was used. Predicted sites with a CFD score $>0.5$ and an MIT score $>0.6$ were chosen for off-target analysis. For analysis, genomic DNA of wildtype and heterozygous mutant Trem2 $\mathrm{R} 47 \mathrm{H}$ mice was isolated and the loci were PCR amplified with primers flanking the putative cut sites. PCR amplicons were subsequently Sanger sequenced using PCR amplification primers and the traces compared to a reference sequence.

\section{Bone marrow derived macrophages culture}

Bone marrow derived macrophages (BMDM) were prepared as previously described [31, 32]. Briefly, the bone marrow cells were flushed out using advanced RPMI 1640 (Life Technologies). Cells were differentiated using advanced RPMI 1640 supplemented with $2 \mathrm{mM} \mathrm{L}$-Glutamine, $10 \%(\mathrm{v} / \mathrm{v}))$ fetal calf serum (FCS), $100 \mathrm{U} / \mathrm{ml}$ penicillin, $100 \mu \mathrm{g} / \mathrm{ml}$ streptomycin and $50 \mathrm{ng} / \mathrm{ml}$ murine M-CSF (R\&D System) for 7 days in non-cell culture treated dishes.

\section{Microglia isolation}

Microglia were isolated as previously described with some modification [33]. Wild type and Trem2 R47H ki mice were perfused with cold phosphate buffered saline (PBS). Whole brain without the cerebellum was cut into small pieces and gently homogenized by mechanical dissociation in homogenization buffer (HBSS no calcium, no magnesium, with phenol red; $15 \mathrm{mM}$ HEPES, $0.6 \%$ glucose). Homogenized cell suspensions were passed through a $100 \mu \mathrm{m}$ cell strainer. Cells were pelleted at $300 \mathrm{~g}$ for $10 \mathrm{~min}$ and the supernatant discarded. To remove myelin, the cell pellets were re-suspended in $22 \%$ percoll (GE Healthcare) and centrifuged for $20 \mathrm{~min}$ at $900 \mathrm{~g}$ (acceleration 4, deceleration 0). Microglia were purified from the pellet using MACS CD11b magnetic beads according to manufacturer's instructions. Briefly, $20 \mu \mathrm{l} \mathrm{CD11b}$ microbeads (Miltenyi) were incubated with cell suspension for $15 \mathrm{~min}$. After incubation, $500 \mu \mathrm{l}$ MACS buffer were added and cells were passed over a pre-rinsed Miltenyi LS column attached to a magnetic field. The column was washed three times with $500 \mu \mathrm{l}$ MACS buffer, removed from the magnetic field and CD11b positive cells were washed out in $5 \mathrm{ml}$ of MACS buffer.

\section{Cell lysis and immunoblotting}

To detect membrane bound Trem2, membrane fractions were collected as previously described [32]. Briefly, cells were lysed in hypotonic buffer $(100 \mathrm{mM}$ Tris- $\mathrm{HCl}, \mathrm{pH} 7.4$, 1 mM EDTA, 1 mM EGTA, pH 7.4) freshly supplemented with a protease inhibitors cocktail (Sigma-Aldrich). Membrane fractions were pelleted by centrifugation for $45 \mathrm{~min}$ at $16,000 \mathrm{~g}$ at $4{ }^{\circ} \mathrm{C}$. Membranes were lysed in STEN lysis buffer $(150 \mathrm{mM} \mathrm{NaCl}, 50 \mathrm{mM}$ Tris- $\mathrm{HCl}, \mathrm{pH}$ 7.6, $2 \mathrm{mM}$ EDTA, 1\% Triton-X 100) on ice for $20 \mathrm{~min}$. Equal amounts of protein were mixed with Laemmli sample buffer supplemented with $\beta$ mercaptoethanol followed by by SDS-PAGE. Proteins were transferred onto polyvinylidene difluoride membranes (Amersham Hybond P 0.45 PVDF, GE Healthcare Life Science) and blocked in 10\% I-BlockTM (Thermo Fisher Scientific) for $1 \mathrm{~h}$. Monoclonal antibody 5F4 (dilution 1:100) [32] was used to detect Trem2.

\section{iPSC generation}

Ethical permission for this study was obtained from the National Hospital for Neurology and Neurosurgery and the Institute of Neurology joint research ethics committee (study reference 09/H0716/64). R47H heterozygous fibroblasts were acquired with a material transfer agreement between University College London and University of California Irvine Alzheimer's Disease Research Center (UCI ADRC; M Blurton-Jones). Fibroblast reprogramming was performed by episomal plasmid nucleofection (Lonza) as previously described [34], using plasmids obtained from Addgene (\#27077, \#27078 and \#27080). Nucleofected cultures were transferred to Essential 8 medium (Life Technologies) after 7 days in vitro (DIV) and individual colonies were picked after 25-30 DIV. All iPSCs were maintained and routinely passaged in Essential 8 medium. Karyotype analysis was performed by The Doctors Laboratory (London, UK). Control iPSC lines used in this study are as follows: CTRL1 (kindly provided by Dr. Selina Wray, UCL Institute of Neurology); CTRL2 (SBAD03, Stembancc); CTRL3 (SFC840, Stembancc); CTRL4 (BIONi010-C, EBiSC).

\section{iPSC-derived microglia-like cells (iMG)}

Using previously described protocols, iPSC-derived microglia-like cells (iMG) were generated [35, 36].

Day 0: iPSC lines were cultured to $60 \%$ confluency in E8 medium on vitronectin-coated 6-well plates. Cells were washed with $\mathrm{PBS}$ (w/o $\mathrm{Ca} 2+/ \mathrm{Mg} 2+)$, followed by trypLE digestion $\left(1 \mathrm{ml} /\right.$ well; $4 \mathrm{~min}$ at $\left.37{ }^{\circ} \mathrm{C}\right)$. The solution was added to 4 volumes of PBS (w/o $\mathrm{Ca} 2+/ \mathrm{Mg} 2+$ ), and triturated to a single cell suspension. The suspension was centrifuged for $3 \mathrm{~min}$ at $300 \mathrm{~g}$ and the cell pellet resuspended in $1 \mathrm{ml}$ EB differentiation medium (Adapted from [36]; EBdiff; Essential 8, $50 \mathrm{ng} / \mathrm{ml}$ BMP-4, $50 \mathrm{ng} / \mathrm{ml}$ VEGF, $20 \mathrm{ng} / \mathrm{ml} \mathrm{SCF}$, and $10 \mu \mathrm{M}$ Y-27632). Cells were counted, and resuspended in EBDiff medium to a density of $10^{5}$ cells $/ \mathrm{ml}$. To generate embryoid bodies (EBs), $100 \mu \mathrm{l}$ of the suspension was added to 96 well ultra-low attachment round bottom tissue culture plates (Corning), centrifuged at $115 \mathrm{~g}$ for $3 \mathrm{~min}$, and transferred to a tissue culture incubator at $37^{\circ} \mathrm{C}$ with $5 \% \mathrm{CO} 2$. 
Day 2: $50 \mu$ of EBdiff medium was added to each well.

Day 3: Dense EBs were formed and collected with a P1000 Gilson pipette into a sterile $15 \mathrm{ml}$ tube, and left to settle. The spent EBdiff medium was discarded and $10 \mathrm{ml}$ of myeloid differentiation medium (Mdiff; X-VIVO 15 medium (Lonza), 1X Glutamax (Life Technologies), $100 \mathrm{U}$ Penicillin/Streptomycin (Life Technologies), $50 \mu \mathrm{M}$ $\beta$-mercaptoethanol (Life Technologies), $100 \mathrm{ng} / \mathrm{ml} \mathrm{MCSF}$ (Peprotech), and 25 ng/ml IL-3 (Cell Guidance Systems)) added. Approximately 150 embryoid bodies $(1.5 \times 96$ well plates) were transferred to a $175 \mathrm{~cm} 2$ flask containing a further $20 \mathrm{ml}$ of Mdiff medium.

Day 9-11: Mdiff medium (30 ml) was added, to avoid acidosis, being careful not to disturb the EBs.

Day 26: Cells were collected from the medium for myeloid marker analysis.

Day 33: Once a week, 1/2 of the Mdiff medium/flask containing budded myeloid cells was collected through a $40 \mu \mathrm{m}$ cell strainer (Falcon, Corning), replacing the collected medium with fresh Mdiff. The myeloid cell suspension was centrifuged for $3 \mathrm{~min}$ at $300 \mathrm{~g}$ and the cell pellet resuspended in $1 \mathrm{ml}$ microglial differentiation medium (Adapted from [35]; MGdiff; DMEM/F12 HEPES no phenol red, 2\% ITS-G (Life Technologies), $1 \%$ N2 supplement (Life Technologies), $200 \mu \mathrm{M}$ monothioglycerol (Sigma), 1X Glutamax, 1X NEAA (Life Technologies), $5 \mu \mathrm{g} / \mathrm{ml}$ Insulin (Sigma), $100 \mathrm{ng} / \mathrm{ml} \mathrm{IL34}$ (Peprotech), $25 \mathrm{ng} / \mathrm{ml} \mathrm{MCSF}$ and $5 \mathrm{ng} / \mathrm{ml}$ TGF $\beta 1$ (Peprotech), filtered through a $0.22 \mu \mathrm{m}$ syringe filter. Cells were counted and plated in MGdiff, and medium replaced every 3-4 days.

Day 46: MGdiff medium was replaced with microglial maturation medium (MGmat: MGdiff + $100 \mathrm{ng} / \mathrm{ml}$ CD200 (Generon), and $100 \mathrm{ng} / \mathrm{ml} \mathrm{CX3CL1} \mathrm{(Peprotech))}$ for 4 days to generate iMG.

\section{Isolation of human blood derived-monocytes}

Monocytes were obtained from blood through centrifugation with Histopaque (Sigma) to isolate peripheral blood mononuclear cells followed by separation and purification with CD14-conjugated magnetic beads (Miltenyi). Peripheral blood monocytes (PBM) were matured into monocyte-derived macrophages (hMacs) in X-VIVO 15 medium with 1\% Glutamax, 100 U Penicillin/Streptomycin, and $100 \mathrm{ng} / \mathrm{ml} \mathrm{MCSF}$ for 7 days.

\section{Microglia signature gene array}

A custom gene array based on published microglial expression data [35, 37-39] was used to confirm a microglial signature in our iMG cultures (TaqMan Array Plate 32 plus Candidate Endogenous Control Genes; Thermo Fisher Scientific). Complementary DNA was generated from iMG, iPSC-derived microglial-like cells [36], and human monocyte-derived macrophages
(hMacs) RNA samples using the High-Capacity RNA-cDNA kit (Life Technologies), according to the manufacturer's instructions. Human primary microglia cDNA was also analyzed as a control sample (ScienCell). Quantitative PCR were conducted on the Mx3000p qPCR system with MxPro qPCR software (Stratagene) using TaqMan Gene Expression Mastermix (Thermo Fisher Scientific). Heat maps were generated with the gplots [40] and d3heatmap [41] packages in R.

Microglial gene signature primer details:

\begin{tabular}{|c|c|}
\hline Gene name & Primer ID \\
\hline $18 \mathrm{~s} r \mathrm{RNA}$ & Hs99999901_s1 \\
\hline GAPDH & Hs99999905_m1 \\
\hline HPRT & Hs99999909_m1 \\
\hline GUSB & Hs99999908_m1 \\
\hline APOE & Hs00171168_m1 \\
\hline C1QA & Hs00706358_s1 \\
\hline $\mathrm{C} 1 \mathrm{QB}$ & Hs00608019_m1 \\
\hline ITGAM & Hs00167304_m1 \\
\hline CSF1R & Hs00911250_m1 \\
\hline CX3CR1 & Hs01922583_s1 \\
\hline GAS6 & Hs01090305_m1 \\
\hline GPR34 & Hs00271105_s1 \\
\hline AlF1 & Hs00610419_g1 \\
\hline MERTK & Hs01031979_m1 \\
\hline OLFML3 & Hs01113293_g1 \\
\hline PROS1 & Hs00165590_m1 \\
\hline SALL1 & Hs01548765_m1 \\
\hline SLCO2B1 & Hs01030343_m1 \\
\hline TGFBR1 & Hs00610320_m1 \\
\hline TMEM119 & Hs01938722_u1 \\
\hline TREM2 & Hs00219132_m1 \\
\hline BIN1 & Hs00184913_m1 \\
\hline CD33 & Hs01076282_g1 \\
\hline SPI1 & Hs02786711_m1 \\
\hline HEXB & Hs01077594_m1 \\
\hline ITM2B & Hs00222753_m1 \\
\hline C3 & Hs00163811_m1 \\
\hline $\mathrm{A} 2 \mathrm{M}$ & Hs00929971_m1 \\
\hline C1QC & Hs00757779_m1 \\
\hline RGS1 & Hs01023772_m1 \\
\hline FTL & Hs00830226_gH \\
\hline P2RY12 & Hs01881698_s1 \\
\hline
\end{tabular}

\section{Immunocytochemistry}

Cells were fixed in 4\% PFA/sucrose in PBS for $20 \mathrm{~min}$ at room temperature (RT), quenched with $50 \mathrm{mM} \mathrm{NH}_{4} \mathrm{Cl}$ 
in PBS for $10 \mathrm{~min}$ at RT, and permebalized with $0.2 \%$ Triton X-100 in PBS for 5 min at RT. Blocking was performed with 5\% normal goat serum (NGS) in PBS for $30 \mathrm{~min}$. Primary antibodies were diluted in 5\% NGS/PBS and incubated at RT for $2 \mathrm{~h}$, followed by PBS washes and incubation with corresponding secondary antibodies for $1 \mathrm{~h}$ at RT in the dark, with gentle rocking. Nuclei were counterstained during mounting using Vectorshield with DAPI (4', 6-diamidino-2-phenylindol; Vector Labs). Fluorescence microscopy was performed on a Zeiss Axioskop 2 microscope and Axiovison software (Zeiss, v4.8). Confocal microscopy was performed on a Zeiss LSM 710 confocal microscope using Zen software (Zeiss, Version 2012), and all images were processed with Image J1.51 K (https:// imagej.nih.gov/ij/). The following antibodies were used: mouse anti-CD68 (1:100, DAKO), rabbit-anti-P2YR12 (1:200, Atlas Antibodies), mouse-anti- $\beta$-Actin (1:500, Sigma), mouse-anti-EZR (1:250, Atlas Antibodies), goat anti-rabbit Alexafluor488 (1:500, Life Technologies), goat-anti-mouse Alexafluor568 (1:500, Life Technologies).

\section{Cellular splicing assay}

Human and mouse Trem 2 genomic fragments encoding exon 1, intron 1, exon 2, and a FLAG tag were synthesized by Integrated DNA Technologies. The following primer sets were used for vector cloning: EcoRV-Hs TREM2-Fw (GGATATCCGGGCAGCGCCTGACATGCCTG) and No tI-Hs TREM2-Rv (ATGCGGCCGCTTAGGATTACAA GGATGACGACGATAAG); HindIII-Mm Trem2 Fw (CC CAAGCTTGGGGCGCCTACCCTAGTCC) and XohvIMm Trem2-Rv (CCGCTCGAGCGGCTACTTGTCGTCA TCG). The amplified fragments were digested by EcoRV/ NotI or HindIII/XohI and the digested fragments were inserted into pcDNA3.1 (+) (Invitrogen). The mutations were introduced in the human and mouse minigene using the Quikchange ${ }^{\mathrm{rm}}$ site-directed mutagenesis kit (Agilent). The following mutants were generated:

(1) $\mathrm{R} 47 \mathrm{H}$ is the $\mathrm{G}>\mathrm{A}$ variant alone encoding arginine;

(2) $\mathrm{R} 47 \mathrm{H}^{\mathrm{TCA}}$ corresponds to sequence variants expressed by the in-house generated Trem $2 \mathrm{R} 47 \mathrm{H}$ ki mice $(\mathrm{GA}>\mathrm{TC}, \mathrm{G}>\mathrm{A}, \mathrm{G}>\mathrm{A}$; also see Fig. 4b);

(3) $\mathrm{R} 47 \mathrm{H}^{\mathrm{AA}}$ represents the Trem $2 \mathrm{R} 47 \mathrm{H}$ ki mice generated by Jackson Laboratory $(\mathrm{G}>\mathrm{A}, \mathrm{G}>\mathrm{A}, \mathrm{C}>$ A; also see Fig. 4b);
(4) TC are the silent mutations in in-house generated Trem2 R47H ki mice (GA > TC)

(5) AA are the silent mutations in Jax R47H ki mice $(\mathrm{G}>\mathrm{A}, \mathrm{C}>\mathrm{A})$.

(6) $\mathrm{R} 47 \mathrm{H}^{\mathrm{T}}$ represents Trem2 $\mathrm{R} 47 \mathrm{H}$ ki mice generated by Cheng Hathaway et al. [26]

For the cellular splicing assay $8 \times 10^{5}$ HEK293 cells were seeded in 6-well plates with Dulbecco's Modified Eagle Medium (Life Technologies) supplemented with GlutaMAX $^{\mathrm{m}}, \quad 10 \% \quad(v / \mathrm{v})$ FCS, $100 \mathrm{U} / \mathrm{ml}$ penicillin, $100 \mu \mathrm{g} / \mathrm{ml}$ streptomycin and cultured overnight. Cells were transfected with $3 \mu \mathrm{g}$ of plasmids to express human or mouse Trem 2 minigenes using $6 \mu$ l lipofectamine 2000 according the manufacturer's instructions (Thermo Fisher Scientific). Transfected cells were cultured in normal medium for $48 \mathrm{~h}$ and collected for RNA extraction using RNeasy Mini Kit (Qiagen) according the manufacturer's instructions. The RNA was used for Reverse transcription polymerase chain reaction (RT-PCR).

\section{Reverse transcription polymerase chain reaction}

$1 \mu \mathrm{g}$ of total RNA was transcribed into cDNA using SuperScript IV reverse transcriptase and oligo dT (Thermo Fisher Scientific). $2 \mu \mathrm{l}$ of cDNA was used as template and amplified by polymerase chain reaction (PCR) with GoTaq DNA polymerase (Promega) according the manufacturer's instructions. The reaction condition and primer sequences are listed in Table 1 . The PCR products were loaded into $2 \%$ agarose gel with GelRed ${ }^{\mathrm{m}}$ (Biotium) for DNA visualization.

\section{Quantitative real-time polymerase chain reaction}

RNeasy Mini Kit (Qiagen) was used for total RNA isolation according the manufacturer's instructions. $1 \mu \mathrm{g}$ of total RNA was transcribed into cDNA using SuperScript IV reverse transcriptase and oligo dT (Thermo Fisher Scientific). RNA levels of human and mouse Trem 2 and Tyrobp were analyzed by Taqman ${ }^{\circ}$ real-time PCR using the 7500 Fast real-time PCR system (Applied Biosystems). For endogenous controls Gusb (Mm01197698_m1, Thermo Fisher Scientific) and Hsp90ab1 (Mm00833431_g1, Thermo Fisher Scientific) or GUSB (Hs00939627_m1, Thermo Fisher Scientific) and HSP90AB1 (Hs03043878_g1, Thermo Fisher Scientific) were used. Probes that target mouse Trem2 and Tyrobp

Table 1 Primers and PCR conditions used for detecting splice pattern (Forward: Fwd; Reverse: Rev)

\begin{tabular}{lll}
\hline Name & Sequence & Reaction condition \\
\hline MmTrem2 Fwd & GCTCAATCCAGGAGCACAGT & $95^{\circ} \mathrm{C} 1 \mathrm{~min} ;\left(95^{\circ} \mathrm{C} 30 \mathrm{~s}, 65^{\circ} \mathrm{C} 15 \mathrm{~s}, 72{ }^{\circ} \mathrm{C} 1 \mathrm{~min}\right) * 35 \mathrm{cycle} ; 72^{\circ} \mathrm{C} 10 \mathrm{~min}$ \\
MmTrem2 Rev & TCTGACACTGGTAGAGGCCC & $95^{\circ} \mathrm{C} 1 \mathrm{~min} ;\left(95^{\circ} \mathrm{C} 30 \mathrm{~s}, 65^{\circ} \mathrm{C} 15 \mathrm{~s}, 72{ }^{\circ} \mathrm{C} 1 \mathrm{~min}\right) * 35 \mathrm{cycle} ; 72{ }^{\circ} \mathrm{C} 10 \mathrm{~min}$ \\
HsTREM2 Fwd & GCCTGACATGCCTGATCCTC & \\
HsTREM2 Rev & AGGACCTTCCTGAGGGTGTC & \\
\hline
\end{tabular}


are Mm04209424_g1, Mm04209423_g1, Mm01273682_g1, Mm00449152_m1 (Thermo Fisher Scientific). Probes that target human TREM2 and TYROBP are Hs01010 721_m1, Hs01003899_m1, Hs00182426_m1 (Thermo Fisher Scientific). For allele specific mRNA expression custom made primers and probes were designed. The primer pair for mouse Trem2 is: CCTTGAGGGTGTCA TGTACTTAT and TCCCATTCCGCTTCTTCAG. The probes for the mouse wild-type allele and $\mathrm{R} 47 \mathrm{H}$ allele are /5HEX/CCTT+G $+\mathrm{C}+\mathrm{GT}+\mathrm{CT}+\mathrm{CC} / 3 \mathrm{IABkFQ} /$ (+, lock nucleic acid) and /56-FAM/CTT + T + G + T + GT $+\mathrm{C}+\mathrm{GA}+\mathrm{C} / 3 \mathrm{IABkFQ} /$, respectively (Integrated DNA Technologies). The primer pair for human TREM2 is ACAAGTTGTGCGTGCTGA and ATGACTCCATGAA GCACTGG. The probes for the human wild-type allele and the $\mathrm{R} 47 \mathrm{H}$ allele are $/ 5 \mathrm{HEX} / \mathrm{CTT}+\mathrm{G}+\mathrm{C}+\mathrm{GCCT}$ $+\mathrm{CC} / 3 \mathrm{IABkFQ} /$ and /56-FAM/TT $+\mathrm{G}+\mathrm{T}+\mathrm{GC}+\mathrm{CT}+$ $\mathrm{CC} / 3 \mathrm{IABkFQ} /$, respectively (Integrated DNA Technologies). The probes and primers were mixed in 1:2 ratios for quantitative PCR reaction.

cDNAs were diluted 1:5 with $\mathrm{H}_{2} \mathrm{O}$ and $9 \mu$ of diluted cDNA together with $1 \mu \mathrm{l}$ of primer probe mix, $10 \mu \mathrm{l}$ of Taqman $^{\oplus}$ master mix (Thermo Fisher Scientific) were used in one $20 \mu \mathrm{l}$ reaction.

\section{Results}

Reduced mRNA and protein level in Trem2 R47H knock-in mice

The rare TREM2 variant rs75932628-T encodes a histidine instead of arginine at position $47(\mathrm{R} 47 \mathrm{H})$ and increases the risk for $\mathrm{AD}$ around three-fold [3, 4]. The DNA and amino acid sequence around arginine at position 47 is highly conserved across different mammalian species (Fig. 1a and b). To study the impact of this variant on TREM2 function in microglia in vivo we generated Trem 2 R47H knock-in mice ( $\mathrm{R} 47 \mathrm{H}$ ki mice) by introducing a $\mathrm{G}>\mathrm{A}$ mutation using the CRISPR/Cas9 technology (Fig. 1c). Two silent mutations were additionally introduced (GA $>$ TC) to create a SalI restriction site for genotyping (Fig. 1c). In addition a silent $\mathrm{G}>$ A mutation was generated to block the protospacer-adjacent motif (PAM) to allow higher gene editing efficiency (Fig. 1c). The predicted potential off-target sites were analyzed. An off-target event with a $\Delta 10$-Indel mutation was identified at an intragenic region on chromosome 11 (Additional file 1: Figure S1, putative off-target \#2). The founder mouse was back-crossed to C57BL/6 N, and off-spring with positive Trem2 R47H ki but negative off-target \#2 (i.e ID-7-1; ID-7-2; ID-7-4) were used for establishing the mouse line. Expression of total Trem 2 mRNA as well as both Trem 2 mRNA transcripts (NM_031254.3 and NM_001272078.1), encoding either membrane bound Trem 2 or a truncated soluble version were validated in brain. Interestingly, total
Trem2 mRNA including both Trem2 transcripts was significantly reduced in a gene dose-dependent manner, whereas mRNA expression of Tyrobp (NM_011662), the adaptor protein of Trem2 [42], remained unchanged (Fig. 1d). Using allele specific qPCR we confirmed that expression of the $\mathrm{R} 47 \mathrm{H}$ allele was selectively reduced compared to the wt allele in heterozygous $\mathrm{R} 47 \mathrm{H}$ ki mice (Fig. 1e and Additional file 2: Table S1).

To confirm decreased Trem2 expression on protein level, we purified microglia from wild-type (wt), heterozygous (het), and homozygous (hom) $\mathrm{R} 47 \mathrm{H}$ ki mice and performed western blotting of membrane fractions. Membrane-bound Trem 2 showed a gene dose-dependent reduction (Fig. 1f).

Reduced Trem 2 R47H mRNA and protein expression was further confirmed in bone marrow derived macrophages (BMDM). Consistent with our findings in brain and microglia, mRNA of both Trem 2 transcripts decreased in a gene dose dependent manner whereas mRNA of Tyrobp remained unchanged (Fig. 1g). Furthermore, immature and mature Trem2 as well as soluble Trem2 (sTrem2) were also reduced in a gene dose dependent manner (Fig. 1h).

To exclude that reduced Trem 2 mRNA and protein expression is artificially caused by the introduction of the three silent mutations, we analyzed Trem $2 \mathrm{R} 47 \mathrm{H}$ knock-in mice generated by Jackson laboratory (Jax $\mathrm{R} 47 \mathrm{H}$ ki mice). In addition to the target variant $\mathrm{R} 47 \mathrm{H}$, these mice harbor two silent mutations (Fig. 2a). One of the silent mutations is a $\mathrm{G}>\mathrm{A}$ exchange to block the PAM sequence exactly like in the mice generated within our laboratory. The second silent mutation $\mathrm{C}>\mathrm{A}$ is only present in the Jax $\mathrm{R} 47 \mathrm{H}$ ki mice (Fig. 2a). We investigated Trem 2 mRNA and protein levels using homozygous Jax R47H ki mice and their wt counterparts. Again, mRNA from total Trem2 as well as from both transcripts of Trem 2 decreased in brains of homozygous ki mice whereas mRNA expression of Tyrobp remained unchanged (Fig. 2b). Western blotting of membrane fractions from BMDM from the Jax $\mathrm{R} 47 \mathrm{H}$ ki mice also confirmed a significant reduction of membrane bound and soluble Trem2 (Fig. 2c). Thus reduction of mRNA and protein levels in Trem $2 \mathrm{R} 47 \mathrm{H}$ ki mouse was confirmed in two independent mouse models.

\section{Aberrant splicing of exon1/2 in Trem2 R47H knock-in mice}

Next we searched for the cellular mechanism responsible for the substantial reduction of the Trem $2 \mathrm{R} 47 \mathrm{H}$ mRNA in the two mouse models. Since nonfunctional mRNAs are rapidly removed by mRNA surveillance systems [43], we studied splicing of the first intron which separates exon 2 containing the $\mathrm{R} 47 \mathrm{H}$ variant from exon 1 harboring the translation initiation site and upstream 


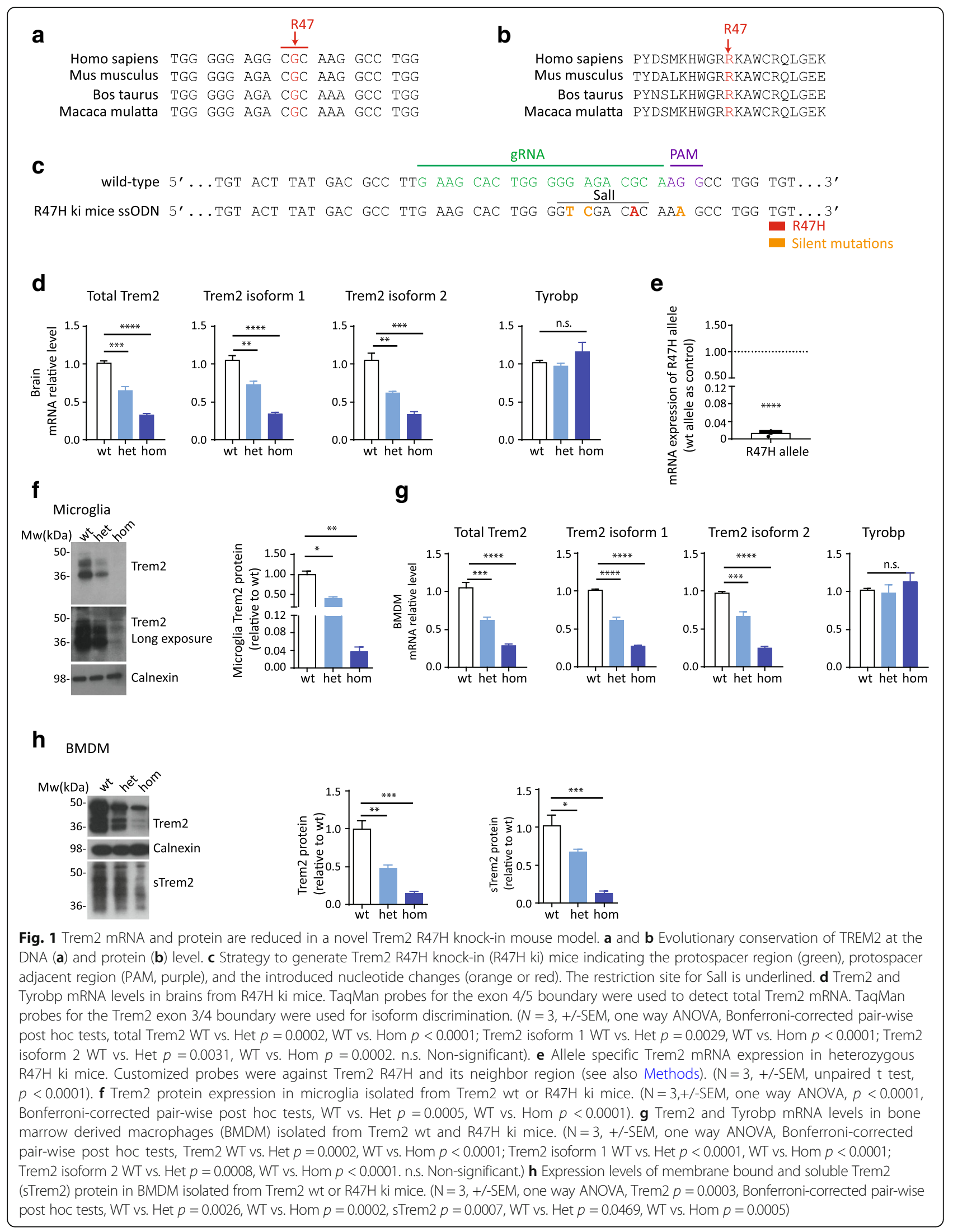




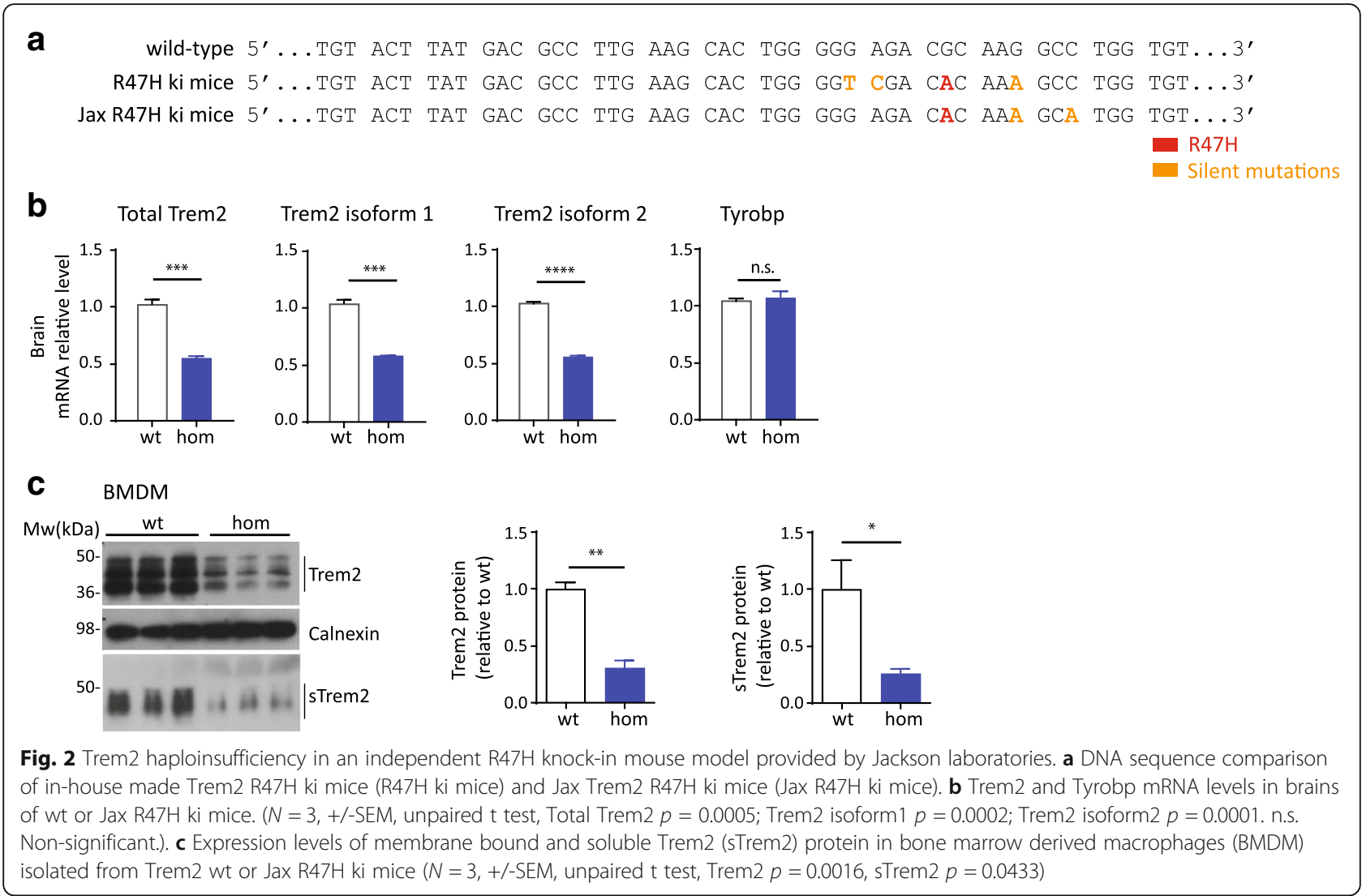

untranslated sequences. Using RT-PCR with primer pairs against the $5^{\prime}$ end of exon 1 and the $3^{\prime}$ end of exon 2 , we compared the splicing patterns of Trem 2 in $\mathrm{R} 47 \mathrm{H}$ ki and wt mice (Fig. 3a). A single splicing product of the expected length (465 base pairs) was obtained from wt Trem2 mRNA (Fig. 3b). Surprisingly, an additional smaller splicing product (346 base pairs) was observed in Trem2 $\mathrm{R} 47 \mathrm{H}$ heterozygous mice, which was even more abundant in Trem2 $\mathrm{R} 47 \mathrm{H}$ homozygous mice (Fig. $3 \mathrm{~b}$ ) while at the same time the larger splicing product was reduced in a gene dose dependent manner (Fig. 3b). This suggests aberrant splicing of Trem 2 pre-mRNA derived from the mutant allele. To independently confirm aberrant splicing, we investigated the Jax R47H ki mice described in Fig. 2. Again, we found an additional smaller RT-PCR product in mutant but not wt mice (Fig. 3c). Furthermore, the larger splicing product was reduced in homozygous ki mice (Fig. 3c). Thus aberrant splicing of $\mathrm{R} 47 \mathrm{H}$ pre-mRNA occurs in two independent mouse models. DNA sequencing of the splicing products revealed correct splicing of exon 1 and exon 2 in wt mice and to a lesser extent also in the ki mice (Fig. 3d). However, DNA sequencing of the additional shorter RT-PCR product of both mutant mice revealed that 119 base pairs were deleted at the $5^{\prime}$ end of exon 2 (Fig. 3d and Additional file 3: Figure S2). The deletion leads to a frame shift and a premature stop codon in exon 2 (Fig. 3d), which may lead to nonsense mediated mRNA decay and thus explain the consistent reduction of the mutant mRNA in both mouse models.

\section{The R47H variant does not affect splicing and mRNA levels in humans}

To directly compare the splicing pattern of mouse and human TREM2 R47H, we expressed mouse or human TREM2 minigenes containing exon 1 , intron 1 , and exon 2 in human embryonic kidney 293 cells (HEK 293) (Fig. 4a). To separately investigate the disease causing TREM2 $\mathrm{R} 47 \mathrm{H}$ variant and the silent mutations, we introduced the corresponding sequence variants either alone or together (Fig. 4b). Upon expression of the minigene encoding the mouse Trem2 sequence, we observed miss-splicing induced by the R47H variant alone (R47H) (Fig. 4c). Similar aberrant splicing was observed when the two silent mutations of the Jax $\mathrm{R} 47 \mathrm{H}$ ki mice were expressed in addition to the $\mathrm{R} 47 \mathrm{H}$ variant $\left(\mathrm{R} 47 \mathrm{H}^{\mathrm{AA}}\right)$, whereas introduction of the two silent mutations alone (AA) did not affect splicing (Fig. 4c). Moreover, when the three silent mutations used to generate our in-house mouse model were combined with the $\mathrm{R} 47 \mathrm{H}\left(\mathrm{R} 47 \mathrm{H}^{\mathrm{TCA}}\right)$, a striking increase of aberrant splicing was observed. When we only introduced the unique TC mutations used to generate our mouse model (TC) we also observed impaired splicing (Fig. 4c), 


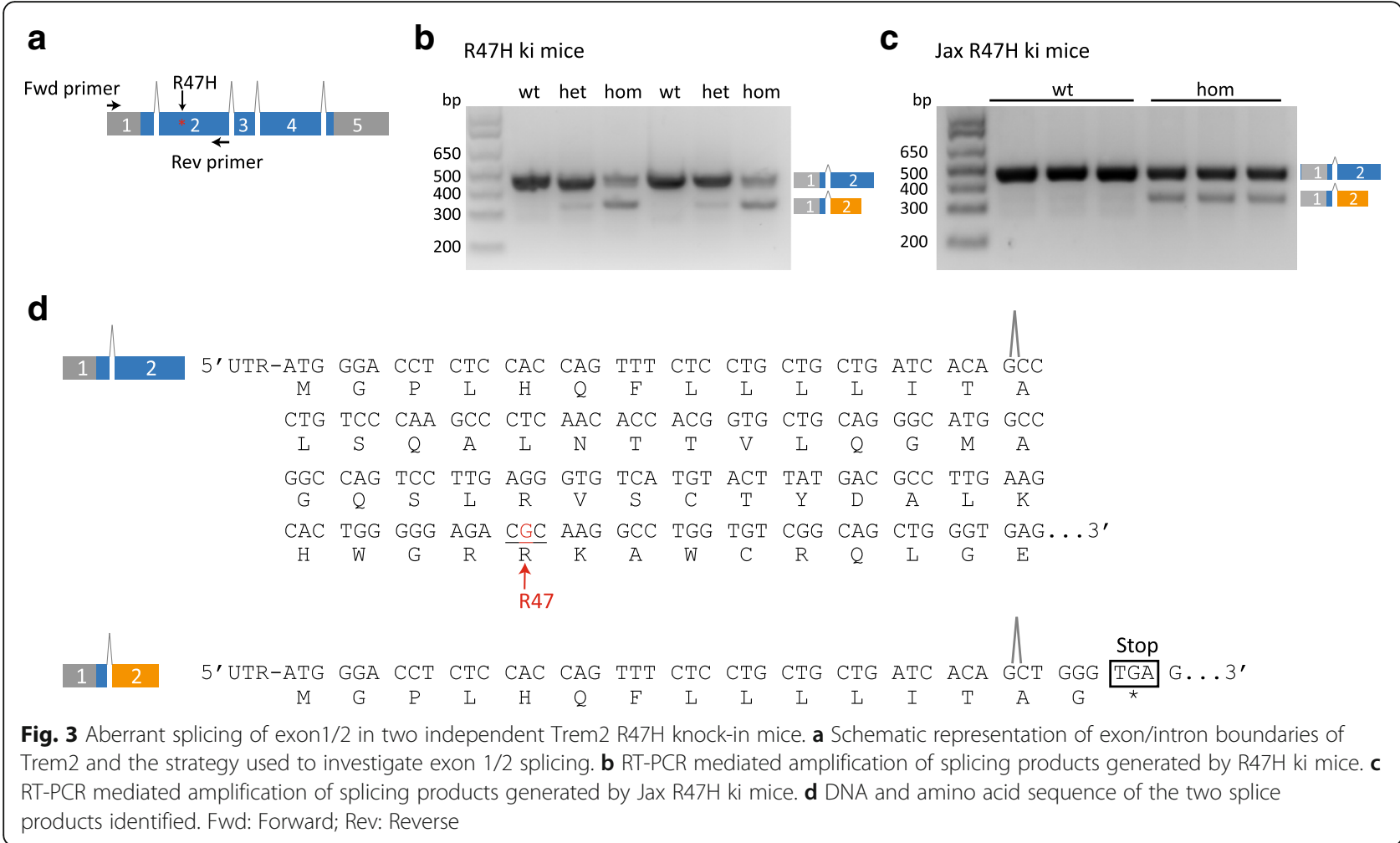

suggesting that $\mathrm{R} 47 \mathrm{H}$ and $\mathrm{TC}$ together display synergistic effects on aberrant splicing. This demonstrates that the $\mathrm{R} 47 \mathrm{H}$ variant by itself is sufficient to induce aberrant splicing, but enhanced miss-splicing upon the addition of silent mutations implies that this genomic region is very sensitive for splicing errors induced by minor changes within the pre-mRNA sequence. Finally, we also investigated if the mutations introduced into the mouse genome by Cheng-hathaway et al. [26] affect pre-mRNA splicing of Trem2. Very similar to our R47H ki mice and those generated by the Jackson Laboratories, the mutations introduced by Cheng-hathaway and colleagues $\left(\mathrm{R} 47 \mathrm{H}^{\mathrm{T}}\right)$ caused aberrant splicing (Fig. 4c), which is consistent with the haploinsuffciency also observed in this model [26].

To prove if this is also true for human TREM2, we investigated the same TREM2 variants in human minigene constructs (Fig. 4a, b and d). Surprisingly, our results demonstrate that neither the $\mathrm{R} 47 \mathrm{H}$ variant alone or in combination with the silent mutations used to generate the ki mouse models affected correct exon1/2 splicing (Fig. 4d). This suggests that only the mouse gene locus is vulnerable for aberrant splicing upon introduction of these sequence variants and implies that the $\mathrm{R} 47 \mathrm{H}$ mutation does not affect splicing and mRNA levels in humans.

To provide direct evidence for this prediction, we investigated exon $1 / 2$ splicing in humanized TREM2 mice generated by ectopic expression of the human wt or R47H mutant TREM2 locus in Trem2 $2^{-/-}$mice [14]. Using the same RT-PCR strategy as described above (Fig. 3a), we could only detect the correctly spliced exon 1 and 2 but no aberrantly spliced additional products (Fig. 5a).

Similarly, in human induced pluripotent stem cell (iPSC)-derived microglia-like cells (iMG) with the wt TREM2 allele or heterozygous for the TREM2 R47H variant (Additional file 4: Figure S3) we also detected only the correctly spliced exon 1 and 2 (Fig. 5b). Furthermore, no aberrant splicing was detected in $\mathrm{AD}$ cases carrying one $\mathrm{R} 47 \mathrm{H}$ mutant allele (Fig. 5c). Direct sequencing demonstrated correct exon1/2 splicing in human iMG and in AD cases. Lack of aberrant splicing of human TREM2 $\mathrm{R} 47 \mathrm{H}$ is consistent with no reduction of total TREM2 mRNA in iMG with one R47H allele (Fig. 5d). In addition, using allele specific qPCR we confirmed that the expression of the $\mathrm{R} 47 \mathrm{H}$ allele is comparable to wt in iMG (Fig. 5e and Additional file 5: Table S2), and in human brain (Fig. $5 \mathrm{f}$ and Additional file 5: Table S2). Taken together, aberrant splicing of $\mathrm{R} 47 \mathrm{H}$ mutant pre-mRNA is not observed in humans and consequently no haploinsufficiency of TREM2 could be detected.

\section{Discussion}

Most functional studies of TREM2 have so far been performed with either total loss-of-function models or by studying the TREM2 T66M mutation $[7,8,11-13$, $19,20,44,45]$, which is associated with an FTD-like syndrome. Homozygous mice expressing the Trem2 T66M 


\section{a}

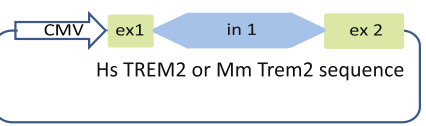

b

Mouse Trem2 sequence

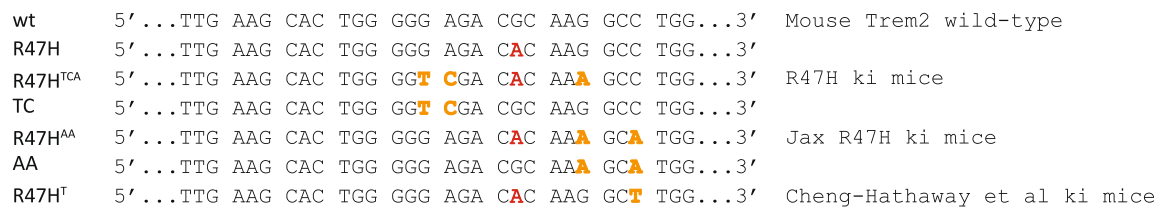

C

HEK293 / Mouse Trem2 minigene

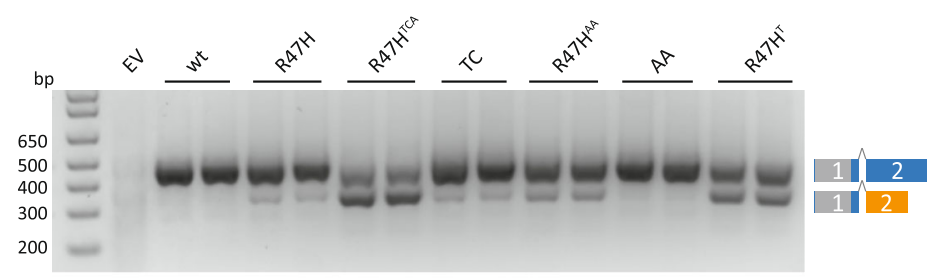

d HEK293 / Human TREM2 minigene

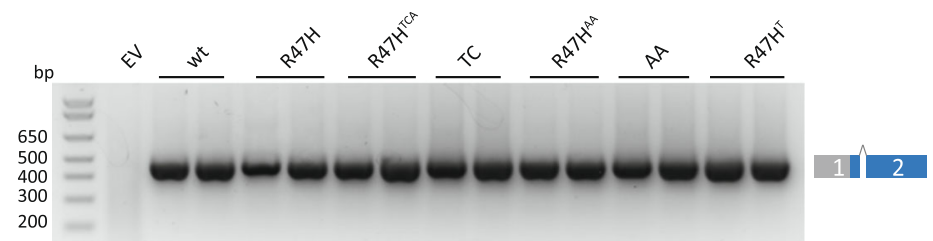

Fig. 4 Aberrant splicing of Trem2 variants containing the R47H mutation with and without additional mutations used to create three different R47H ki mice. a The minigene construct used to investigate exon1/2 splicing of the Trem2 variants shown in (b). b Sequence alignment of Trem2 variants investigated for aberrant splicing. c Exon 1/2 splicing of mouse Trem2 variants described in (b). d Exon 1/2 splicing of human TREM2 variants described in (b). Note that only mouse transcripts undergo aberrant splicing. EV: empty vector

variant phenocopy a number of functional deficits also observed upon total loss of the Trem2 encoding gene [11]. These include delayed resolution of inflammation upon lipopolysaccharide stimulation, reduced phagocytic activity, reduced microglial activation during physiological ageing and neurological insults, reduced cerebral blood flow, reduced cerebral brain glucose metabolism, impaired chemotaxis and clustering of microglia around amyloid plaques [11]. However, much less is known about the functional impact of the TREM2 R47H variant, which is associated with a high risk for AD similar to that caused by the ApoE $\varepsilon 4$ allele $[3,4,46]$. In vitro studies suggested reduced binding of $\mathrm{A} \beta$ oligomers, ApoE, and phosphatidylserine due to structural alterations in TREM2 [8, 21-24]. Furthermore maturation of the R47H variant within the secretory pathway may also be delayed [25]. Expression of human TREM2 R47H in Trem2 knockout mice failed to rescue the knockout phenotypes again supporting the notion that TREM2 is protective and that TREM2 variants associated with neurodegenerative diseases may cause a loss-of-function [14]. Trem2 R47H knock-in mice expressing this variant under physiological conditions resulted in phenotypes that were compatible with a loss-of function [26]. Cheng-Hathaway et al. 


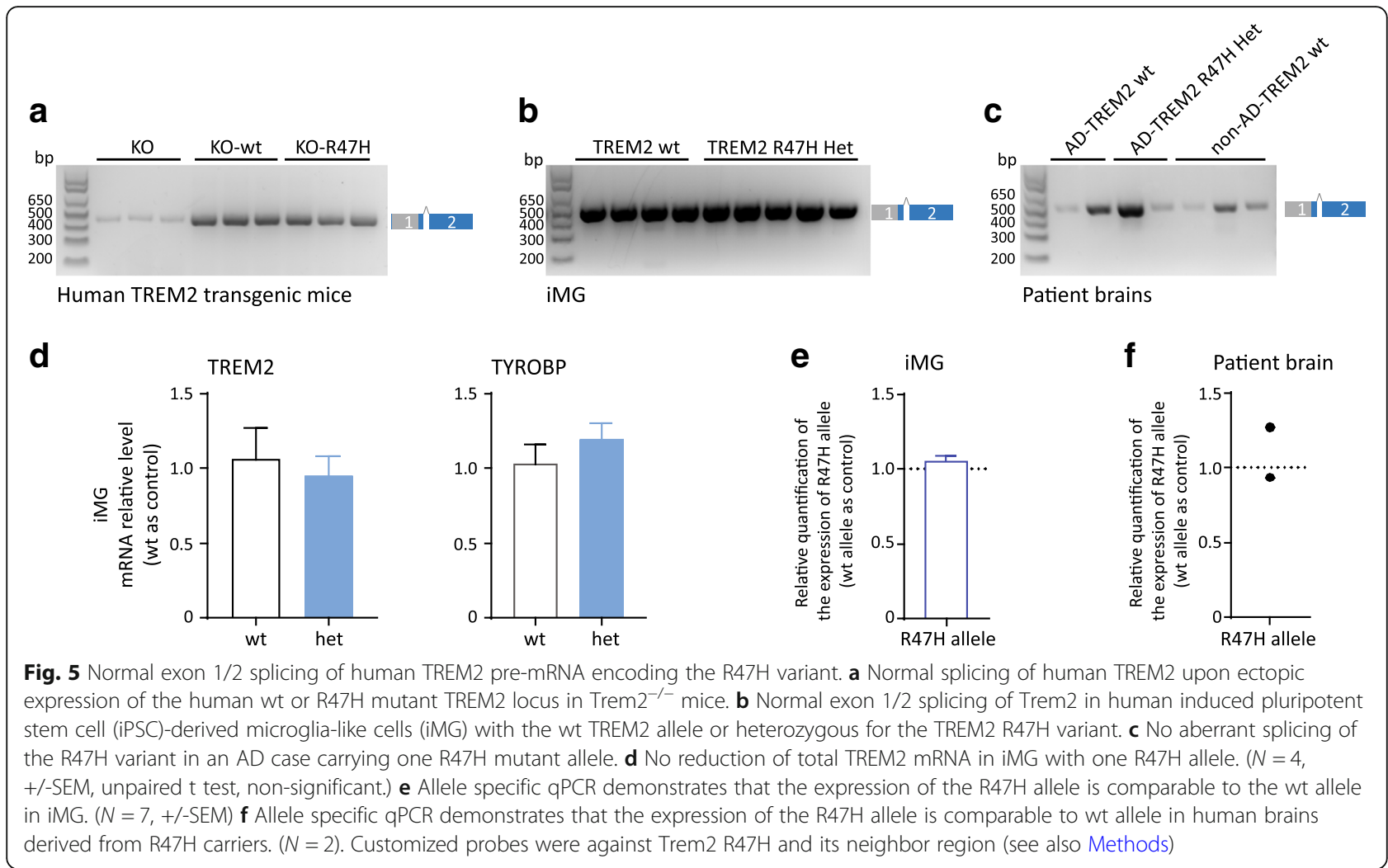

reported that Trem2 $\mathrm{R} 47 \mathrm{H}$ heterozygous mice showed reduced Trem2 expression in microglia close to amyloid plaques, reduced microglial proliferation, reduced dense core plaques and increased neuritic dystrophy [26]. These phenotypes were associated with reduced Trem 2 mRNA expression [26]. Similarly, Sudom et al. reported reduced Trem2 protein expression in brain as well as reduced sTrem2 in plasma from R47H knock-in mice [24]. All together, this suggests that the $\mathrm{AD}$-associated Trem2 $\mathrm{R} 47 \mathrm{H}$ variant is also associated with a loss-of-function. However, while the T66M mutation causes a loss-of-function due to retention of the misfolded mutant protein within the endoplasmatic reticulum $[11,25]$, the $\mathrm{R} 47 \mathrm{H}$ mutation appears to cause haploinsufficiency due to reduced mRNA levels [26]. We generated a similar mouse model using the CRISPR/ Cas9 technology. Consistent with published findings, our mouse model also showed reduced Trem 2 mRNA and protein levels. Furthermore, similar findings were made using an independent mouse generated by Jackson Laboratories. We therefore searched for a joined cellular mechanism, which may be involved in the significant reduction of Trem2 mRNA and protein in both mouse models. Surprisingly, we found that the introduction of the $\mathrm{R} 47 \mathrm{H}$ variant by itself but even more so the introduction of additional silent mutations caused aberrant splicing. Direct sequencing of the aberrant splicing product revealed that it lacks 119 base pairs. Close inspection of the sequence of the alternative splice product revealed that a cryptic splice acceptor site within the exon 2 was activated. This leads to the elimination of parts of exon 2 resulting in a splicing product containing a premature stop codon. It is well known that such aberrant mRNAs are rapidly degraded by nonsense-mediated mRNA decay [47]. Note that the TaqMan probes used for detecting Trem2 mRNA were either bound to exon $3 / 4$ or exon $4 / 5$ boundary (Fig. 1d) thus they detect both the full length functional Trem 2 mRNA and the aberrantly spliced shorter variant. Therefore, the apparent degree of reduction for Trem2 mRNA and protein is not equal (Fig. 1d and f). However, we cannot fully exclude the possibility that the $\mathrm{R} 47 \mathrm{H}$ variant may also affect mouse Trem 2 protein stability.

The mRNA reductions caused by aberrant splicing, which were consistent in two independent mouse models, led us to investigate if aberrant exon 2 splicing in humans also leads to TREM2 haploinsufficiency. We found that TREM2 mRNA levels and splicing patterns were both normal in iPSC-derived human microglia-like cells and in patient brains with the TREM2 R47H variant. Furthermore, cellular splicing assays using minigene constructs demonstrate that the $\mathrm{R} 47 \mathrm{H}$ variant induced abnormal splicing only occurs in mice but not in humans. Thus, both the $\mathrm{R} 47 \mathrm{H}$ variant as well as additionally introduced silent variants cause a mouse-specific reduction of Trem2 mRNA. Therefore, these findings cannot be translated to humans calling for novel humanized R47H mouse models. 


\section{Conclusions}

The AD-associated Trem2 $\mathrm{R} 47 \mathrm{H}$ variant in combination with silent mutations introduced by the CRISPR/Cas9 technology causes mouse specific aberrant splicing of exon 2, which leads to an alternative Trem 2 mRNA containing a premature stop codon. The observed significant reduction of Trem 2 mRNA and protein in $\mathrm{R} 47 \mathrm{H}$ ki mice is most likely the consequence of nonsense-mediated mRNA decay of the aberrant transcript and is not observed in human systems. Thus, functional data derived from Trem2 $\mathrm{R} 47 \mathrm{H}$ knock-in mice cannot be translated to humans.

\section{Additional files}

Additional file 1: Figure S1. Off-target analysis of in-house made Trem2 $\mathrm{R} 47 \mathrm{H}$ knock-in mice. a Sanger-sequencing chromatograms of the Trem2 on-target site and the six putative off target sites of animal Trem2 R47H ki ID-7. Mixed peaks in the Trem2 locus show the correct R47H substitution (CGC > CAC) and the three silent mutations for genotyping purposes. Mixed peaks in traces of site \#2 reveal a $\Delta 10$-Indel mutation at the putative cut site, indicating a true off target event. Underlined: Protospacer; arrow head: putative cut site; green letters: PAM site on shown strand; red letters: PAM site on complementary strand; yellow: $\Delta 10$ Indel mutation. $\mathbf{b}$ Sanger sequencing results of Trem2 R47H positive offsprings of male ID-7, which was crossed with a C57BL/ $6 \mathrm{~N}$ female. The $\Delta 10$ Indel allele was inherited to animals ID-7-3 und ID-7-12 that were excluded from any further breedings and experiments. (PDF $201 \mathrm{~kb}$ )

Additional file 2: Table S1. Allele specific quantitative PCR for Trem2 R47H knock-in mice (PDF 92 kb)

Additional file 3: Figure S2. Sequence of the aberrantly spliced murine Trem2 mRNA. Trem2 gene sequence. Exon in black; intron in green; // indicates splicing sites. (PDF $93 \mathrm{~kb}$ )

Additional file 4: Figure S3. iMG differentiation and validation. a Schematic of the in vitro differentiation of iPSC-derived microglia-like cells (iMG). (i): Human iPSCs are grown in feeder free conditions with no spontaneous differentiation. Scale bar: $250 \mu \mathrm{m}$. (ii): Embryoid bodies are formed in the presence of 3 factors SCF, BMP4, and VEGF; Scale bar: $750 \mu \mathrm{m}$. (iii): Myeloid cells are generated after culturing with IL3 and MCSF growth factors for 3-4 weeks, then stained for classic myeloid/ macrophage markers CD68. Scale bar: $50 \mu \mathrm{m}$. (iv): Further differentiation to microglia-like cells that positive for microglial markers P2RY12. Scale bar: $20 \mu \mathrm{m}$. (v): Addition of the two final factors (CD200 and CX3CL1) matures the iMG. Scale bar: $20 \mu \mathrm{m}$. $\mathbf{b}$ Heat map showing mRNA expression of a microglial gene signature in $\mathrm{MMG}$, human monocyte-derived macrophages (hMac), human primary microglia (hMG), and iPSC samples. Clear clustering is observed between iMG and hMG. (PDF $159 \mathrm{~kb}$ )

Additional file 5: Table S2. Allele specific quantitative PCR for iMG and patient brains (PDF $104 \mathrm{~kb}$ )

\section{Abbreviations}

AD: Alzheimer's disease; Aß: Amyloid $\beta$-peptide; BMDM: Bone marrow derived macrophages; HEK293: Human embryonic kidney 293; Hom: Homozygous; iMG: iPSC derived microglia-like cells; iPSC: Induced pluripotent stem cell; ki: Knock-in; PAM: Protospacer-adjacent motif; qPCR: Quantitative polymerase chain reaction; RT-PCR: Reverse transcriptase polymerase chain reaction; sTREM2: Soluble TREM2; TREM2: Triggering receptor expressed on myeloid cell 2; WT: Wild-type; Het: heterozygous

\section{Acknowledgements}

The authors thank the Queen Square Brain Bank for access to tissue: this resource is funded in part by the Weston Foundation and the MRC.

\section{Funding}

This work was supported by the Deutsche Forschungsgemeinschaft (DFG) within the framework of the Munich Cluster for Systems Neurology (EXC
1010 SyNergy) and the Koselleck Project HA1737/16-1 (to C.H.). This work was funded in part by the German Federal Ministry of Education and Research (BMBF) through the Joint Project HIT-Tau TP2: Grant 01EK1605C to W. W. This work was supported by the Biotechnology and Biological Sciences Research Council (grant number BB/M009513/1) to A.M. and by funding from the Innovative Medicines Initiative 2 Joint Undertaking under grant agreement No 115976 (for T.P to J.P). This Joint Undertaking receives support from the European Union's Horizon 2020 research and innovation programme and EFPIA. This work was funded by NIH grant RF1 AG051485 to M.C.

\section{Availability of data and materials}

The datasets used and/or analyzed during the current study are available from the corresponding author on reasonable request.

\section{Authors' contributions}

$\mathrm{XX}$ designed and conceived the study. $\mathrm{XX}$ and $\mathrm{CH}$ interpreted the results. $\mathrm{CH}$ and $X X$ wrote the manuscript with input from all co-authors. BW and WW generated the Trem2 R47H knock-in mice. GK and BW analyzed potential offtargets. XX, KZ and $\mathrm{JH}$ prepared bone marrow and isolated microglia from mice. $X X$ and BB performed RNA analyses and immunoblotting. XX performed RT-PCR, allele specific qPCR and cellular splicing analysis. TP, AM and JP generated the iPSC derived microglia-like cells and performed GPCR on these cells. MC and WS provided the mouse brain samples from humanized TREM2 mice. All authors read and approved the final manuscript.

\section{Ethics approval}

All mice were handled according to institutional guidelines approved by the animal welfare and use committee of the government of Upper Bavaria. Ethics committee from Ludwig-Maximilians- University and University College London approved this research project using human tissue.

\section{Consent for publication}

Consent for publication on using human tissue in this study is detailed in the Material Transfer Agreement (MTA) between organizations.

\section{Competing interests}

C.H. collaborates with DENALI Therapeutics and received a speaker honorarium from Novartis and Roche. The other authors declare that they have no competing interests.

\section{Publisher's Note}

Springer Nature remains neutral with regard to jurisdictional claims in published maps and institutional affiliations.

\section{Author details}

${ }^{1}$ Metabolic Biochemistry, Biomedical Center (BMC), Faculty of Medicine, Ludwig-Maximilians-Universität München, Munich, Germany. ${ }^{2}$ Graduate School of Systemic Neuroscience, Ludwig- Maximilians- University Munich, Munich, Germany. ${ }^{3}$ Department of Neuroinflammation, Cell Signalling Lab, University College London Institute of Neurology, WC1N 1PJ, London, UK. ${ }^{4}$ German Center for Neurodegenerative Diseases (DZNE) Munich, Munich, Germany. ${ }^{5}$ Munich Cluster for Systems Neurology (SyNergy), Munich, Germany. ${ }^{6}$ Institute of Developmental Genetics, Helmholtz Zentrum München, German Research Center for Environmental Health, Neuherberg, Germany. ${ }^{7}$ Department of Immunology and Pathology, Washington University in St. Louis, St. Louis, MO, USA. ${ }^{8}$ Center for Neuropathology and Prion Research, Ludwig-Maximilians-Universität München, Munich, Germany. ${ }^{9}$ Technische Universität München-Weihenstephan, 85764 Neuherberg/ Munich, Germany.

Received: 8 August 2018 Accepted: 21 August 2018

Published online: 06 September 2018

\section{References}

1. Sims R, Van Der Lee SJ, Naj AC, Bellenguez C, Badarinarayan N, Jakobsdottir J, et al. Rare coding variants in PLCG2, ABI3, and TREM2 implicate microglial-mediated innate immunity in Alzheimer's disease. Nat Genet. [Internet] 2017;49:1373-84. Available from: https://www.ncbi.nlm.nih.gov/ pubmed/28714976.

2. Jiang $T$, Tan $\mathrm{L}$, Chen $\mathrm{Q}$, Tan MS, Zhou JS, Zhu XC, et al. A rare coding variant in TREM2 increases risk for Alzheimer's disease in Han Chinese. Neurobiol 
Aging [Internet]. Elsevier Inc. 2016;42:17.e1-217.e3. Available from: https:// doi.org/10.1016/j.neurobiolaging.2016.02.023.

3. Jonsson T, Stefansson H, Steinberg S, Jonsdottir I, Jonsson PV, Snaedal J, et al. Variant of TREM2 associated with the risk of Alzheimer's disease. N Engl J Med. [Internet]. 2013;368:107-16. Available from: http://www.ncbi. nlm.nih.gov/pubmed/23150908.

4. Guerreiro R, Wojtas A, Bras J, Carrasquillo M, Rogaeva E, Majounie E, et al. TREM2 variants in Alzheimer's disease. N Engl J Med [Internet]. 2013;368:117-27. Available from: http://www.nejm.org/doi/abs/10.1056/NEJMoa1211851.

5. Chan G, White CC, Winn P a, Cimpean M, Replogle JM, Glick LR, et al. CD33 modulates TREM2: convergence of Alzheimer loci. Nat. Neurosci. [Internet]. 2015;2015. Available from: https://doi.org/10.1038/nn.4126.

6. Krasemann S, Madore C, Cialic R, Baufeld C, Calcagno N, El Fatimy R, et al. The TREM2-APOE Pathway Drives the Transcriptional Phenotype of Dysfunctional Microglia in Neurodegenerative Diseases. Immunity [Internet]. Elsevier Inc.; 2017;47:566-81.e9. Available from: http://inkinghub.elsevier. com/retrieve/pii/S1074761317303667.

7. Mazaheri F, Snaidero N, Kleinberger G, Madore C, Daria A, Werner G, et al. TREM2 deficiency impairs chemotaxis and microglial responses to neuronal injury. EMBO Rep [Internet] 2017;18:1186-98. Available from: http://embor. embopress.org/lookup/doi/10.15252/embr.201743922.

8. Wang Y, Cella M, Mallinson K, Ulrich JD, Young KL, Robinette ML, et al. TREM2 Lipid Sensing Sustains the Microglial Response in an Alzheimer's Disease Model. Cell [Internet]. Elsevier Inc.; 2015;160:1061-71. Available from: http://linkinghub.elsevier.com/retrieve/pii/S0092867415001270.

9. Ulland TK, Song WM, Huang SCC, Ulrich JD, Sergushichev A, Beatty WL, et al. TREM2 Maintains Microglial Metabolic Fitness in Alzheimer's Disease. Cell [nternet]. Elsevier Inc; 2017;170:649-63.e13. Available from: https://doi.org/10.1016/j.cell.2017.07.023.

10. Keren-Shaul H, Spinrad A, Weiner A, Matcovitch-Natan O, Dvir-Szternfeld R, Ulland TK, et al. A Unique Microglia Type Associated with Restricting Development of Alzheimer's Disease. Cell [Internet]. Elsevier; 2017;169:127690.e17. Available from: https://doi.org/10.1016/j.cell.2017.05.018.

11. Kleinberger G, Brendel M, Mracsko E, Wefers B, Groeneweg L, Xiang X, et al. The FTD-like syndrome causing TREM2 T66M mutation impairs microglia function, brain perfusion, and glucose metabolism. EMBO J [Internet] 2017; 36:1837-53. Available from: http://emboj.embopress.org/lookup/doi/10. 15252/embj.201796516.

12. Jay TR, Miller CM, Cheng PJ, Graham LC, Bemiller S, Broihier ML, et al. TREM2 deficiency eliminates TREM2+ inflammatory macrophages and ameliorates pathology in Alzheimer's disease mouse models. J Exp Med [Internet] 2015; 212:287-95. Available from: http://www.jem.org/cgi/doi/10.1084/jem.20142322.

13. Yuan P, Condello C, Keene CD, Wang Y, Bird TD, Paul SM, et al. TREM2 Haplodeficiency in mice and humans impairs the microglia barrier function leading to decreased amyloid compaction and severe axonal dystrophy. Neuron [Internet]. 2016;92:252-64. Available from: https://www.ncbi.nlm.nih. gov/pubmed/27196974.

14. Song WM, Joshita S, Zhou Y, Ulland TK, Gilfillan S, Colonna M. Humanized TREM2 mice reveal microglia-intrinsic and -extrinsic effects of R47H polymorphism. J. Exp. med. [Internet]. 2018;215:745-60. Available from: http://www.ncbi.nlm.nih.gov/pubmed/29321225.

15. Suárez-Calvet M, Araque Caballero MÁ, Kleinberger G, Bateman RJ, Fagan AM, Morris JC, et al. Early changes in CSF sTREM2 in dominantly inherited Alzheimer's disease occur after amyloid deposition and neuronal injury. Sci. Transl. Med. [lnternet]. 2016;8:369ra178. Available from: http://www.ncbi.nlm. nih.gov/pubmed/27974666.

16. Wang Y, Ulland TK, Ulrich JD, Song W, Tzaferis JA, Hole JT, et al. TREM2mediated early microglial response limits diffusion and toxicity of amyloid plaques. J Exp Med. [Internet]. 2016;jem.20151948. Available from: http:// www.jem.org/lookup/doi/10.1084/jem.20151948.

17. Cantoni C, Bollman B, Licastro D, Xie M, Mikesell R, Schmidt R, et al. TREM2 regulates microglial cell activation in response to demyelination in vivo. Acta Neuropathol. [Internet]. 2015;129:429-47. Available from: http://www. ncbi.nlm.nih.gov/pubmed/25631124.

18. Poliani PL, Wang Y, Fontana E, Robinette ML, Yamanishi Y, Gilfillan S, et al. TREM2 sustains microglial expansion during aging and response to demyelination. J Clin Invest. [Internet]. 2015;125:2161-70. Available from: http://www.ncbi.nlm.nih.gov/pubmed/25893602.

19. Bemiller SM, McCray TJ, Allan K, Formica SV, Xu G, Wilson G, et al. TREM2 deficiency exacerbates tau pathology through dysregulated kinase signaling in a mouse model of tauopathy. Mol Neurodegener. [lnternet] 2017:12:1-12. Available from: https:/www.ncbinlm.nih.gov/pubmed/29037207.
20. Leyns CEG, Ulrich JD, Finn MB, Stewart FR, Koscal LJ, Remolina Serrano J, et al. TREM2 deficiency attenuates neuroinflammation and protects against neurodegeneration in a mouse model of tauopathy. Proc. Natl. Acad. Sci. U. S. A. [Internet]. 2017;114:11524-9. Available from: http://www.pnas.org/ lookup/doi/10.1073/pnas.1710311114.

21. Atagi Y, Liu C-C, Painter MM, Chen X-F, Verbeeck C, Zheng H, et al. Apolipoprotein $\mathrm{E}$ is a ligand for triggering receptor expressed on myeloid cells 2 (TREM2). J Biol Chem. [Internet] 2015;290:26043-50. Available from: https://www.ncbi.nlm.nih.gov/pubmed/26374899.

22. Yeh FL, Wang Y, Tom I, Gonzalez LC, Sheng M. TREM2 binds to apolipoproteins, including APOE and CLU/APOJ, and thereby facilitates uptake of amyloid-Beta by microglia. Neuron. [Internet] 2016;91:328-40. Available from: https://www.ncbi.nlm.nih.gov/pubmed/27477018.

23. Zhao $Y$, Wu X, Li X, Jiang L-L, Gui $X$, Liu Y, et al. TREM2 Is a Receptor for $\beta$ Amyloid that Mediates Microglial Function. Neuron [Internet]. 2018;97:1023-31. e7. Available from: http//linkinghub.elsevier.com/retrieve/pii/S0896627318300564.

24. Sudom A, Talreja S, Danao J, Bragg E, Kegel R, Min X, et al. Molecular basis for the loss-of-function effects of the Alzheimer's disease-associated R47H variant of the immune receptor TREM2. J Biol Chem. [internet]. 2018;2:jbc.RA118. 002352. Available from: http://www.ncbi.nlm.nih.gov/pubmed/29794134.

25. Kleinberger $\mathrm{G}$, Yamanishi $\mathrm{Y}$, Suárez-Calvet $\mathrm{M}, \mathrm{Cz}$ irr E, Lohmann E, Cuyvers $\mathrm{E}$, et al. TREM2 mutations implicated in neurodegeneration impair cell surface transport and phagocytosis. Sci. Transl. Med. [Internet]. 2014;6:243ra86. Available from: http://www.ncbi.nlm.nih.gov/pubmed/24990881.

26. Cheng-hathaway PJ, Reed-geaghan EG, Jay TR, Casali BT, Bemiller SM, Puntambekar SS, et al. The T rem 2 R47H variant confers loss-of- functionlike phenotypes in Alzheimer's disease. Mol Neurodegener. [Internet] 2018: 1-12. Available from: https://www.ncbi.n/m.nih.gov/pubmed/29859094.

27. Cheng Q, Danao J, Talreja S, Wen P, Yin J, Sun N, et al. TREM2-activating antibodies abrogate the negative pleiotropic effects of the Alzheimer's disease variant TREM2 ${ }^{\mathrm{R} 4 \mathrm{HH}}$ on murine myeloid cell function. J Biol Chem. [Internet]. 2018;jbc.RA118.001848. Available from: http://www.jbc.org/ lookup/doi/10.1074/jbc.RA118.001848.

28. Brandl C, Ortiz O, Röttig B, Wefers B, Wurst W, Kühn R. Creation of targeted genomic deletions using TALEN or CRISPR/Cas nuclease pairs in one-cell mouse embryos. FEBS Open Bio [Internet]. Federation of European Biochemical Societies; 2015;5:26-35. Available from: https://doi.org/10.1016/j.fob.2014.11.009.

29. Wefers B, Bashir S, Rossius J, Wurst W, Kühn R. Gene editing in mouse zygotes using the CRISPR/Cas9 system. Methods [Internet]. Elsevier Inc. 2017;121-122: 55-67. Available from: https://doi.org/10.1016/j.ymeth.2017.02.008.

30. Haeussler M, Schönig K, Eckert H, Eschstruth A, Mianné J, Renaud JB, et al. Evaluation of off-target and on-target scoring algorithms and integration into the guide RNA selection tool CRISPOR. Genome Biol. [Internet] 2016; 17(1):148. Available from: https://doi.org/10.1186/s13059-016-1012-2.

31. Marim FM, Silveira TN, Lima DS, Zamboni DS. A method for generation of bone marrow-derived macrophages from cryopreserved mouse bone marrow cells. PLoS One. [Internet] 2010;5:1-8. Available from: https://www. ncbi.nlm.nih.gov/pubmed/21179419.

32. Xiang X, Werner G, Bohrmann B, Liesz A, Mazaheri F, Capell A, et al. TREM2 deficiency reduces the efficacy of immunotherapeutic amyloid clearance. EMBO Mol. Med. [Internet] 2016;8:992-1004. Available from: https://www. ncbi.nlm.nih.gov/pubmed/27402340.

33. Galatro TF, Vainchtein ID, Brouwer N, Boddeke EWGM, Eggen BJL. Isolation of microglia and immune infiltrates from mouse and primate central nervous system. Methods Mol Biol. [lnternet] 2017;1559:333-42. Available from: https://www.ncbi.nlm.nih.gov/pubmed/28063055.

34. Okita K, Matsumura Y, Sato Y, Okada A, Morizane A, Okamoto S, et al. A more efficient method to generate integration-free human iPS cells. Nat methods [Internet]. 2011;8:409-12. Available from: http://www.ncbi.nlm.nih. gov/pubmed/21460823.

35. Abud EM, Ramirez RN, Martinez ES, Healy LM, Nguyen CHH, Newman SA, et al. iPSC-Derived Human Microglia-like Cells to Study Neurological Diseases. Neuron. [Internet] 2017;94:278-293.e9. Available from: https:// www.ncbi.nlm.nih.gov/pubmed/28426964.

36. van Wilgenburg B, Browne C, Vowles J, Cowley SA. Efficient, long term production of monocyte-derived macrophages from human pluripotent stem cells under partly-defined and fully-defined conditions. Covas DT, editor. PLoS One. [Internet] 2013;8:e71098. Available from: http://www.ncbi. nlm.nih.gov/pubmed/23951090.

37. Butovsky O, Jedrychowski MP, Moore CS, Cialic R, Lanser AJ, Gabriely G, et al. Identification of a unique TGF- $\beta$-dependent molecular and functional 
signature in microglia. Nat Neurosci [Internet] 2014;17:131-43. Available from: http://www.pubmedcentral.nih.gov/articlerender.fcgi?artid= 4066672\&tool=pmcentrez\&rendertype $=$ abstract.

38. Muffat J, Li Y, Yuan B, Mitalipova M, Omer A, Corcoran S, et al. Efficient derivation of microglia-like cells from human pluripotent stem cells. Nat Med. [Internet] 2016;22:1358-67. Available from: https://www.ncbi.nIm.nih. gov/pubmed/27668937.

39. Haenseler W, Sansom SN, Buchrieser J, Newey SE, Moore CS, Nicholls FJ, et al. A highly efficient human pluripotent stem cell microglia model displays a neuronal-co-culture-specific expression profile and inflammatory response. Stem Cell Rep. [Internet] 2017;8:1727-42. Available from: https:/ www.ncbi.n/m.nih.gov/pubmed/28591653.

40. CRAN - Package gplots [Internet]. Available from: https://cran.r-project.org/ web/packages/gplots/index.html.

41. R package d3heatmap version 0.6.1.2. Comprehensive R Archive Network (CRAN). Available from: https://cran.r-project.org/web/packages/d3heatmap/ index.html.

42. Bouchon A, Hernández-Munain C, Cella M, Colonna M. A DAP12-mediated pathway regulates expression of $C C$ chemokine receptor 7 and maturation of human dendritic cells. J Exp Med. [Internet] 2001;194:1111-22. Available from: http://www.pubmedcentral.nih.gov/articlerender.fcgi?artid= 2193511\&tool=pmcentrez\&rendertype $=$ abstract

43. Isken O, Maquat LE. Quality control of eukaryotic mRNA: safeguarding cells from abnormal mRNA function. Genes Dev. [Internet] 2007;21:1833-56. Available from: https:/www.ncbi.nlm.nih.gov/pubmed/17671086.

44. Jay TR, Hirsch AM, Broihier ML, Miller CM, Neilson LE, Ransohoff RM, et al. Disease progression-dependent effects of TREM2 deficiency in a mouse model of Alzheimer's disease. J Neurosci. [Internet] 2017;37:637-47. Available from: http://www.jneurosci.org/content/37/3/637.

45. Wang Y, Ulland TK, Ulrich JD, Song W, Tzaferis JA, Hole JT, et al. TREM2mediated early microglial response limits diffusion and toxicity of amyloid plaques. J Exp Med. [Internet]. 2016;213:667-75. Available from: http://www. jem.org/lookup/doi/10.1084/jem.20151948.

46. Colonna M, Wang Y. TREM2 variants: new keys to decipher Alzheimer disease pathogenesis. Nat. Rev. Neurosci. [Internet]. Nat Publ Group; 2016;17:201-207. Available from: http://www.nature.com/doifinder/10.1038/nrn.2016.7.

47. Maquat LE. Nonsense-mediated mRNA decay in mammals. J Cell Sci. [Internet] 2005;1 18:1773-6. Available from: http://jcs.biologists.org/cgi/doi/ $10.1242 / \mathrm{jcs} .01701$.

Ready to submit your research? Choose BMC and benefit from:

- fast, convenient online submission

- thorough peer review by experienced researchers in your field

- rapid publication on acceptance

- support for research data, including large and complex data types

- gold Open Access which fosters wider collaboration and increased citations

- maximum visibility for your research: over $100 \mathrm{M}$ website views per year

At BMC, research is always in progress.

Learn more biomedcentral.com/submissions 